\title{
STUDI REKAYASA LALU LINTAS PADA SIMPANG TUJUH ULEE KARENG DENGAN MERENCANAKAN BUNDARAN (ROUNDABOUT)
}

\author{
Ruhdi Faisal $^{1)}$, Sugiarto Sugiarto ${ }^{2)}$, Zulfhazli $^{3)}$, Muhammad Irza ${ }^{4)}$ \\ ${ }^{1,2)}$ Jurusan Teknik Sipil, Universitas Syiah Kuala \\ ${ }^{3)}$ Jurusan Teknik Sipil, Universitas Malikussaleh \\ ${ }^{4)}$ Alumni, Jurusan Teknik Sipil, Universitas Syiah Kuala \\ Corresponding email:ruhdi.faisal@unsyiah.ac.id
}

DOI: http://dx.doi.org/10.29103/tj.v9i1.177

\begin{abstract}
Abstrak
Simpang Tujuh Ulee Kareng merupakan persimpangan dengan jumlah pertemuan ruas jalan yang paling banyak di Kota Banda Aceh tanpa adanya pengaturan lalu lintas, sehingga mengakibatkan terjadi tundaan dan kemacetan. Tujuan dari penelitian ini adalah untuk membuat sebuah rekayasa lalu lintas dari simpang tak bersinyal menjadi persimpangan dengan bundaran. Data volume lalu lintas diambil dengan bantuan kamera video dan data kecepatan diambil dengan alat bantu speedgun. Data yang dikumpulkan adalah data geometrik jalan, volume lalu lintas dan kecepatan setempat. Data awal yang digunakan untuk adalah volume jam puncak (VJP) dari volume yang diamati dan kemudian disimulasikan ke software VISSIM 6.00-22 dengan tipe bundaran R10-22. Kapasitas terbesar di ruas jalinan yaitu $6629 \mathrm{kend} / \mathrm{jam}$. Arus bagian jalinan terbesar di ruas jalinan $\mathrm{AB}$ yaitu $3184 \mathrm{kend} / \mathrm{jam}$. Tundaan terbesar di ruas jalinan AB yaitu 2,30 detik/kendaraan. Untuk Derajat Kejenuhan (DS) didapat dari perbandingan arus bagian jalinan dengan kapasitas. DS terbesar di ruas jalinan AB yaitu 0,50 dan Peluang Antrian terbesar dari pembacaan grafik MKJI adalah 6\%$13,5 \%$.
\end{abstract}

Kata kunci: Bundaran, Simulasi, Derajat Kejenuhan, VISSIM 6.00-22, Simpang Tujuh.

\begin{abstract}
The Simpang Tujuh Ulee Kareng is a complex intersection consisted of seven approaches without the traffic arrangements, so it may causesignificant delay and traffic congestion during peak hour operation. The aim of this research was to manage and evaluate a traffic operation of unsignalized intersection at the Simpang Tujuh Ulee Kareng from with the application of roundabout. Traffic volume data was taken by video camera and speed data taken by speed gun. The collected data were road geometric data, traffic volume and spot speed. The primary data for analysis needs was taken at peak hour volume of the observed volume and then simulated to the VISSIM 6.00-22 software with Roundabout type R10-22. The largest capacity in the DE segment was 6629 vehicle/hour. The largest weaving flow in the weaving section $\mathrm{AB}$ was 3184 vehicle/hour. The largest delayed in the weaving section was 2,30 seconds/vehicle. The calculation of Degree of Saturation (DS) was obtained from the comparison of flow section with capacity. The largest DS was weaving section with DS of 0.50 and the Probability of Queuing obtained by using MKJI traffic code was $6 \%-13.5 \%$.
\end{abstract}

Keywords: roundabout, simulation,degree of saturation, VISSIM 6.00-22, Simpang Tujuh.

Studi Rekayasa Lalu Lintas Pada Simpang Tujuh Ulee Kareng Dengan Merencanakan Bundaran (Roundabout) - Ruhdi Faisal, Sugiarto Sugiarto, Zulfhazli, Muhammad Irza 


\section{Latar Belakang}

Kemacetan lalu lintas ditinjau dari sisi mikroskopis dapat diakibatkan oleh adanya gangguan parkir dipinggir jalan, aktivitas lalu lintas pada segmen u-turn dan pada persimpangan. Pengaruh aktivitas u-turn dan parkir dipinggir jalan sangat signifikan terhadap karakteristik dan kualitas pelayanan jalan terutama pada jam puncak di Banda Aceh (Sugiarto $d k k$., 2012; Sugiarto $d k k$., 2013). Lalu lintas pada persimpangan memiliki karakteristik yang sangat komplek terutama pada simpang tak bersinyal dan daerah jalinan (bundaran).Simpang adalah titik simpul dalam jaringan jalan dimana dua atau lebih ruas jalan bertemu yang fungsinya untuk melakukan perubahan arah lalu lintas. Hampir semua jaringan jalan kita dapati adanya persimpangan yang terletak pada bidang yang sama dan kebanyakan dari arus lalu lintas tersebut berpotongan, sehingga banyak terjadinya konflik yang pada akhirnya menyebabkan kemacetan/tundaan dan terkadang kecelakaan.Bundaran juga dapat mengurangi potensi kecelakaan dikarenakan pergerakan kendaraan masuk ke daerah jalinan akan mengalami merging atau weaving dengan kecepatan yang relatif rendah (Troutbeck dan Brilon, 2001).

Pada penelitian ini yang ditinjau merupakan persimpangan yang mempunyai tujuh lengan yaitu Simpang Tujuh Ulee Kareng. Simpang Tujuh Ulee Kareng merupakan persimpangan dengan jumlah pertemuan ruas jalan yang paling banyak di Kota Banda Aceh. Simpang Tujuh Ulee Kareng terdiri dari pertemuan tujuh ruas jalan diantaranya Jalan T. Iskandar (arah kota), Jalan Mesjid Tuha, Jalan Lamreung, Jalan Kebun Raja, Jalan Lamgapang, Jalan Jurong Dagang dan Jalan T. Iskandar (arah Blang Bintang). Simpang Tujuh Ulee Kareng menjadi kawasan perdagangan dan jasa yang ramai dimana daerah ini memiliki kegiatan finansial dan peluang - peluang bisnis yang ekstensif dimana kompleksitas dan diversitasnya mengalami siklus perubahan akibat beragam pengaruh sosial dan ekonomi.

Pada Simpang Tujuh Ulee Kareng terjadi pertemuan ruas jalan yang sangat komplek karena terdiri dari pertemuan tujuh ruas jalan tanpa adanya pengaturan lalu lintas seperti lampu lalu lintas, bundaran, maupun rambu-rambu peringatan lainnya. Kondisi ini sangat mengganggu pengguna jalan apalagi pada jam - jam puncak (peak hour). Pengguna jalan harus ekstra hati-hati pada jangka waktu tersebut karena tidak adanya pengaturan lalu lintas sehingga rawan terjadi kecelakaan. Penelitian ini bertujuan untuk membuat sebuah rekayasa lalu lintas terhadap Simpang Tujuh Ulee Kareng dari simpang tak bersinyal menjadi sebuah persimpangan dengan bundaran. Hal tersebut merupakan suatu upaya untuk memberikan suatu rekomendasi untuk mengurangi atau mencegah terjadinya konflik pada persimpangan tersebut.

Sugiarto dkk., (2018) mempelajari karakteristik lalu lintas di Bundaran Lambaro, Aceh Besar. Mereka mengalibrasi kembali angka ekuivalensi mobil penumpang (EMP) menggunakan data okupansi yang diobservasi menggunakan drone. Mereka menyimpulkan faktor konversi EMP sangat signifikan mempengaruhi dalam analisis kapasitas dan kinerja Bundaran. Bundaran memberikan kapasitas lebih baik dibandingkan dengan simpang tak bersinyal pada kondisi volume lalu lintas rendah (Sonu $d k k$., 2016). Penelitian sebelumnya yang terlah mempelajari karakteristik lalu lintas bundaran dengan mengalibrasi 
kembali faktor ekuivalensi mobil penumpang dan pengaruhnya pada kapasitas bundaran (Arasan dan Arkatkar (2010), Praveen dan Arasan (2013), Sugiarto dkk., (2018)).

Menurut Drew dalam buku Ahmed (2005) menyatakan bahwa simulasi didefinisikan sebagai representasi yang dinamis dari beberapa bagian yang nyata di dunia dicapai dengan membangun sebuah permodelan pada komputer bergerak melalui waktu. Menurut PTV-AG (2015), VISSIM adalah Multi-moda lalu lintas perangkat lunak aliran mikroskopis simulasi. Hal ini dikembangkan oleh (Planning Transportasi Verkehr AG) di Karlsruhe Jerman. Nama ini berasal dari "Verkehr Stadten-SIMulationsmodell" (bahasa Jerman untuk "Lalu lintas di kotamodel simulasi"). Program ini dapat menganalisis lalu lintas dan operasi perjalanan yang masih terkendala seperti konfigurasi jalur, komposisi kendaraan, sinyal lalu lintas dan halte sehingga membuatnya menjadi alat yang berguna untuk evaluasi berbagai alternatif berdasarkan rekayasa transportasi dan langkahlangkah perencanaan efektivitas.

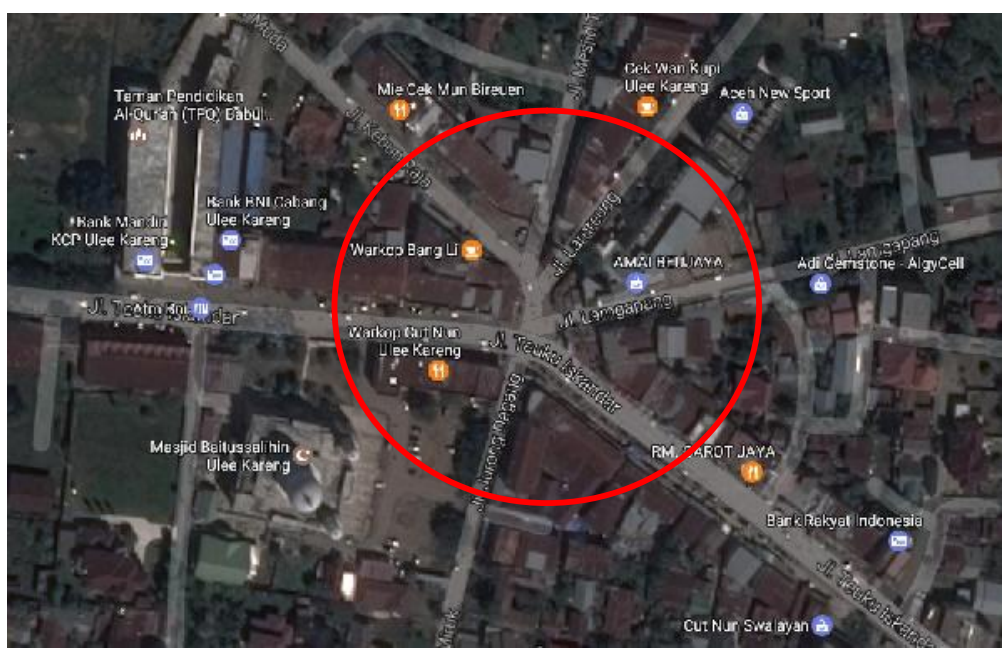

Gambar 1 Peta Lokasi Penelitian Simpang 7 Ulee Kareng, Kota Banda Aceh

(C) 2018 Google earth).

\section{Metode Penelitian}

Penelitian ini diawali dengan rumusan latar belakang seperti yang disampaikan pada bab pendahuluan. Kemudian dilanjutkan dengan pengumpulan data primer dan data sekunder terlebih dahulu untuk selanjutnya dilakukan pengolahan data dan analisis data, kemudian akan dilanjutkan penyusunan kesimpulan beserta saran oleh peneliti.

\subsection{Pengumpulan Data}

Data primer adalah data yang diperoleh langsung dari hasil pengamatan di lapangan. Adapun data primer pada penelitian ini adalah sebagai berikut:

1. Geometrik jalan diperoleh dengan mengukur menggunakan pita meter.

Berikut data lebar jalur pada masing-masing ruas jalan di Simpang 7 Ulee Kareng diperlihatkan pada Tabel 1. 
Tabel 1 Lebar Jalur pada masing-masing ruas jalan di Simpang 7 Ulee Kareng

\begin{tabular}{clcc}
\hline \multirow{2}{*}{ No } & \multicolumn{1}{c}{ Ruas Jalan } & $\begin{array}{c}\text { Tipe } \\
\text { Jalan }\end{array}$ & $\begin{array}{c}\text { Lebar } \\
\text { jalur }(\mathrm{m})\end{array}$ \\
\hline 1 & Jalan T. Iskandar (Arah Pusat Kota Banda Aceh) & $4 / 2 \mathrm{UD}$ & 8 \\
\hline 2 & Jalan Kebun Raja & $2 / 2 \mathrm{UD}$ & 6 \\
\hline 3 & Jalan Mesjid Tuha & $2 / 2 \mathrm{UD}$ & 4 \\
\hline 4 & Jalan Lamreung & $2 / 2 \mathrm{UD}$ & 6 \\
\hline 5 & Jalan Lamgapang & $2 / 2 \mathrm{UD}$ & 5 \\
\hline 6 & Jalan T. Iskandar (Arah Blang Bintang) & $4 / 2 \mathrm{D}$ & 10 \\
\hline 7 & Jalan Jurong Dagang & $2 / 2 \mathrm{UD}$ & 5 \\
\hline
\end{tabular}

2. Volume lalu lintas yang didapat dengan mengunakan alat bantu kamera video, volume yang dihitung berupa yaitu sepeda motor (MC) kendaraan ringan (LV) dan kendaraan berat (HV). Pengambilan data dilakukan selama dua hari, dimulai dari pagi pukul 07.00 - 09.00 WIB dan sore pukul 16.30 - 18.30 WIB. Pada jam-jam tersebut diperkirakan terjadinya peak hour (jam puncak).

3. Kecepatan setempat didapat dengan menggunakan alat bantu speedgun. Kecepatan yang diamati pada studi kasus ini untuk jalan per satu arah adalah kecepatan setempat. Pengukuran kecepatan dilakukan dengan menggunakan alat speedgun. Data kecepatan diamati pada tiap jalur saat kendaraan menuju dan keluar dari persimpangan. Sampel yang diambil sebanyak 60 (enam puluh) kendaraan pada tiap lajur.

Data sekunder adalah data yang diperoleh dari instansi-instansi terkait untuk mendukung penelitian ini adalah sebagai berikut:

1. Peta Kota Banda Aceh yang diperoleh dari google maps

2. Peta lokasi pengamatan jalan yang diteliti (Simpang Tujuh Ulee Kareng).

3. Sketsa lokasi penelitian (Simpang Tujuh Ulee Kareng).

\subsection{Pengolahan Data dan Pemodelan}

Metode yang digunakan pada proses pengolahan data pada Simpang Tujuh Ulee Kareng yaitu dengan pengolahan data primer berupa pengolahan data volume lalu lintas untuk mendapatkan kapasitas dan derajat kejenuhan. Dan untuk pengolahan data kecepatan setempat digunakan untuk menginput kecepatan pada simulasi VISSIM 6.00-22. Data yang dihasilkan berupa volume lalu lintas dan kecepatan setempat berdasarkan hasil survei lapangan, kemudian data ini digunakan sebagai acuan hasil penelitian ini. Volume lalu lintas tersebut dikonversikan ke dalam ekuivalensi mobil penumpang (EMP) untuk jalan dua jalur satu arah.

Pengolahan data dilakukan setelah data-data hasil pengamatan di lapangan telah direkapitulasi sehingga data tersebut dapat dianalisis dan dapat disimulasikan dengan menggunakan softwareVISSIM 6.00-22. Berikut ini adalah tahapan-tahapan mendesain VISSIM 6.00-22 untuk menjalankan simulasi dan mendapat video visualisasi aliran lalu lintas, yaitu:

1. Meng-input background

2. Pembentukan jaringan jalan (network coding);

3. Membangun ruas penghubung (link-connectors);

4. Menentukan jumlah kendaraan (vehicle input);

5. Meng-input kecepatan kendaraan (desired speed);

Studi Rekayasa Lalu Lintas Pada Simpang Tujuh Ulee Kareng Dengan Merencanakan Bundaran (Roundabout) - Ruhdi Faisal, Sugiarto Sugiarto, Zulfhazli, Muhammad Irza 
6. Meng-input komposisi kendaraan (vehicle composition);

7. Menentukan rute perjalanan (vehicle route);

8. Meng-input komposisi rute perjalanan;

9. Melakukan kalibrasi (driving behavior calibration);

10. Pengaturan jumlah trial simulasi (rundom seeds \& simulation runs);

11. Menjalankan simulasi (simulation runs).

Kalibrasi yang telah dilakukan dalam penelitian ini adalah kalibrasi parameter dan validasi faktor random simulasi dengan penggandaan random seed. Sedangkan validasi adalah perbandingan parameter aliran lalu lintas yang diperoleh dari lapangan terhadap hasil simulasi dengan menggunakan VISSIM 6.00-22 dapat diterima apabila hasil yang dicapai lebih kecil dari $15 \%$ seperti yang direkomendasikan oleh (Collins, 2009:61).

\section{Hasil dan Pembahasan}

\subsection{Volume Lalu Lintas}

Survei volume lalu lintas dilakukan pada hari Senin 6 Maret 2017 dan kamis 9 Maret 2017. Berdasarkan hasil pengolahan data yang diperoleh di lapangan, volume kendaraan tertinggi saat jam puncak arus lalu lintas yang terjadi pada hari Senin (6 Maret 2017) dengan total $3943 \mathrm{kend} / \mathrm{jam}$ melintas pada pagi hari pukul 07.00 - $09.00 \mathrm{WIB}$ dan $4619 \mathrm{kend} / \mathrm{jam}$ pada sore hari pukul 16.30 - 18.30 WIB.

Pergerakan tertinggi yang terjadi pada hari Senin dan akan diambil volume jam puncak (VJP) dengan interval waktu satu jam yang selanjutnya akan digunakan sebagai data input untuk proses simulasi menggunakan software VISSIM 6.00-22.Data volume lalu lintas diperoleh dengan mencatat semua jenis kendaraan yang melintasi titik pias pengamatan dalam interval waktu 15 menit kemudian diolah menjadi volume lalu lintas dalam interval waktu satu jam. Rekapitulasi data volume lalu lintas pada jam puncak dapat diperlihatkan pada Tabel 2.

Tabel 2 Rekapitulasi volume lalu lintas

\begin{tabular}{clc}
\hline No. & Hari/Tanggal & $\begin{array}{c}\text { Arus Maksimum } \\
\text { (kend/jam) }\end{array}$ \\
\hline 1. & Senin/06 Maret 2017 & 4619 \\
\hline 2. & Kamis/09 Maret 2017 & 4566 \\
\hline
\end{tabular}

\subsection{Kecepatan Setempat}

Perhitungan besarnya kecepatan setempat didapat dengan menggunakan speedgun, dengan jarak pengambilan $25 \mathrm{~m}$ dari simpang. Untuk mendapatkan kecepatan setempat diambil 60 kendaraan yang melintasi setiap lengan tersebut. Rekapitulasi perhitungan kecepatan setempat selama satu hari pengamatan dapat dilihat pada Tabel 3.

Tabel 3 Rekapitulasi Kecepatan lalu lintas

\begin{tabular}{clcc}
\hline No. & Jalan & $\begin{array}{c}\text { Lebar } \\
\text { Jalur }(\mathbf{m})\end{array}$ & $\begin{array}{c}\text { Kecepatan } \\
(\mathbf{K m} / \mathbf{j a m})\end{array}$ \\
\hline 1 & Jalan T. Iskandar (Arah Pusat Kota Banda Aceh) & 8 & 17,19 \\
\hline 2 & Jalan Kebun Raja & 6 & 22,27 \\
\hline
\end{tabular}

Studi Rekayasa Lalu Lintas Pada Simpang Tujuh Ulee Kareng Dengan Merencanakan Bundaran (Roundabout) - Ruhdi Faisal, Sugiarto Sugiarto, Zulfhazli, Muhammad Irza 


\begin{tabular}{llcc}
\hline 3 & Jalan Mesjid Tuha & 4 & 21,4 \\
\hline 4 & Jalan Lamreung & 6 & 22,61 \\
\hline 5 & Jalan Lamgapang & 5 & 22,74 \\
\hline 6 & Jalan T. Iskandar (Arah Blang Bintang) & 10 & 20,24 \\
\hline 7 & Jalan Jurong Dagang & 5 & 21,31 \\
\hline
\end{tabular}

\subsection{Volume Jam Puncak}

Volume jam puncak digunakan sebagai dasar untuk perancangan jalan raya dan berbagai macam analisis operasional. Jalan raya harus dirancang sedemikian rupa sehingga mampu melayani pada saat lalu lintas pada kondisi volume jam puncak. Untuk analisis operasional, apakah itu terkait dengan pengendalian, keselamatan, kapasitas, maka jalan raya harus mampu mengakomodasi kondisi ketika volume jam puncak. Rekapitulasi volume jam puncak pada Tabel 4.

Tabel 4 Rekapitulasi Volume Jam Puncak (17.00-18.00)

\begin{tabular}{clc}
\hline No. & \multicolumn{1}{c}{ Jalan } & $\begin{array}{c}\text { Volume } \\
\text { (Kend/Jam) }\end{array}$ \\
\hline 1 & Jalan T. Iskandar (Arah Pusat Kota Banda Aceh) & 1861 \\
\hline 2 & Jalan Kebun Raja & 290 \\
\hline 3 & Jalan Mesjid Tuha & 229 \\
\hline 4 & Jalan Lamreung & 407 \\
\hline 5 & Jalan Lamgapang & 430 \\
\hline 6 & Jalan T. Iskandar (Arah Blang Bintang) & 1440 \\
\hline 7 & Jalan Jurong Dagang & 478 \\
\hline
\end{tabular}

\subsection{Penentuan Ukuran Bundaran}

Bundaran paling efektif jika digunakan untuk persimpangan antara jalan dengan ukuran dan tingkat arus yang sama. Karena itu bundaran sangat sesuai untuk persimpangan antara jalan dua lajur atau empat lajur. Bundaran mempunyai keuntungan yaitu mengurangi kecepatan semua kendaraan yang berpotongan, dan membuat mereka hati-hati terhadap risiko konflik dengan kendaraan lain. Anonim (1997) memberikan sejumlah tipe bundaran untuk perencanaan yang dapat dilihat pada Tabel 5.

Tabel 5 Tipe Bundaran

\begin{tabular}{lccccc}
\hline $\begin{array}{c}\text { Tipe } \\
\text { bundaran }\end{array}$ & $\begin{array}{c}\text { Jari-jari } \\
\text { bundaran }(\mathrm{m})\end{array}$ & $\begin{array}{c}\text { Jumlah lajur } \\
\text { masuk }\end{array}$ & $\begin{array}{c}\text { Lebar lajur } \\
\text { masuk } \\
\mathrm{W}_{\mathrm{I}}(\mathrm{m})\end{array}$ & $\begin{array}{c}\text { Panjang } \\
\text { jalinan } \mathrm{L}_{\mathrm{W}} \\
(\mathrm{m})\end{array}$ & $\begin{array}{c}\text { Lebar } \\
\text { jalinan } \\
\mathrm{W}_{\mathrm{W}}(\mathrm{m})\end{array}$ \\
\hline $\mathrm{R} 10-11$ & 10 & 1 & 3,5 & 23 & 7 \\
\hline $\mathrm{R} 10-22$ & 10 & 2 & 7 & 27 & 9 \\
\hline $\mathrm{R} 14-22$ & 14 & 2 & 7 & 31 & 9 \\
\hline $\mathrm{R} 20-22$ & 20 & 2 & 7 & 43 & 9 \\
\hline
\end{tabular}

Setelah data geometrik, volume lalu lintas dan pergerakan untuk eksisting diketahui, data tersebut digunakan untuk data masukan perencanaan simpang dengan bundaran, sehingga dari MKJI didapatkan tipe bundaran R10-11. Tipe bundaran R10-11 tidak dapat digunakan karena tipe tersebut memiliki lebar 
jalinan 7 meter yang berarti lebih kecil dari pada lebar lengan masuk T. Iskandar (Arah Blang Bintang) 10 meter (4/2D). Jadi, tipe bundaran yang diambil R10-22, dengan lebar jalinan 9 meter dan apron 2 meter untuk radius putar kendaraan berat. Gambar 2 merupakan gambar rencana bundaran dengan perubahan geometrik beberapa lengan jalan.

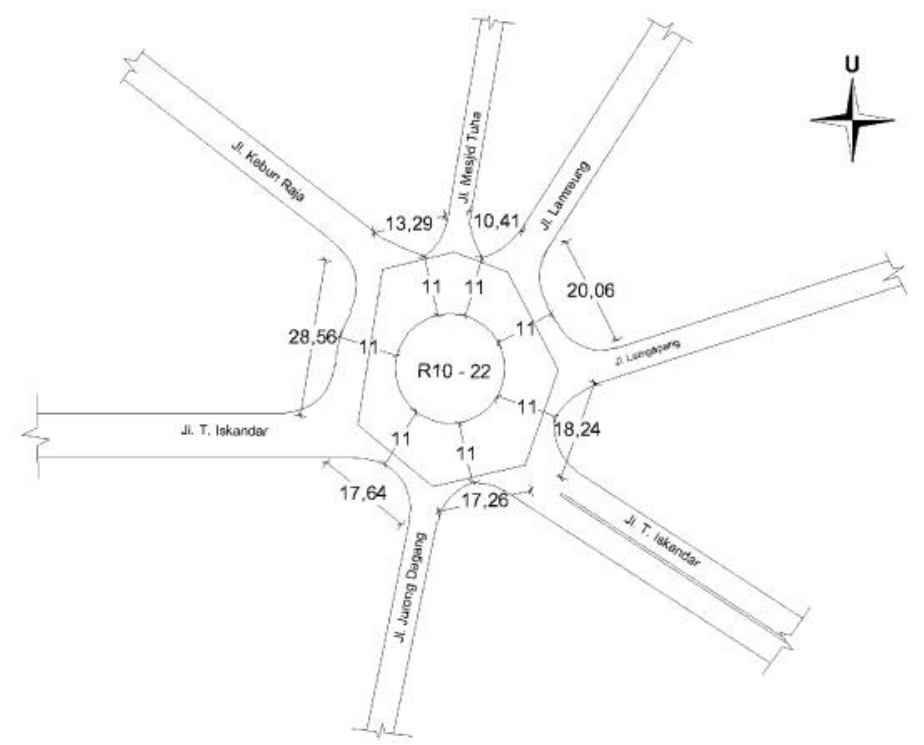

Gambar 2 Geometrik Rencana Bundaran Simpang 7 Ulee Kareng

\subsection{Distribusi Pergerakan Kendaraan}

Distribusi ini merupakan distribusi pergerakan volume jam puncak. Data ini digunakan sebagai data input VISSIM 6.00-22 dapat dilihat pada Tabel 6.

Tabel 6 Distribusi pergerakan kendaraan ke masing-masing lengan

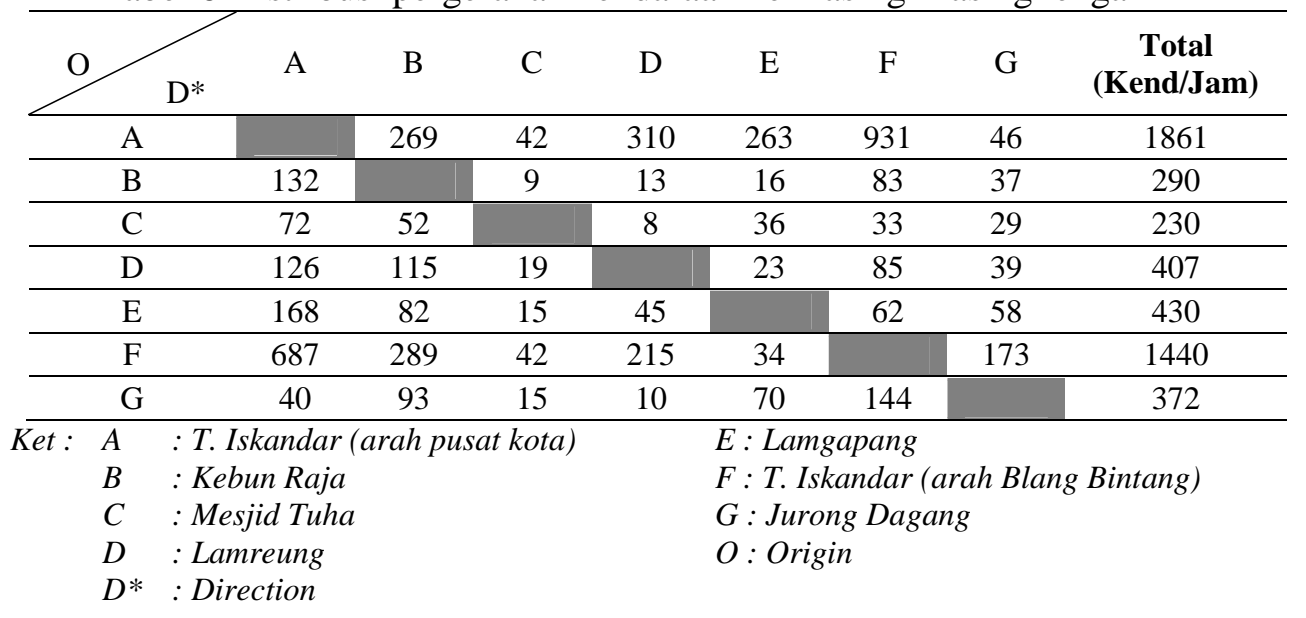

\subsection{Simulasi dan Hasil VISSIM 6.00-22}

\subsubsection{Arus Jalinan Bundaran}

Berdasarkan data yang input ke VISSIM didapat arus jalinan pada tiap ruas, arus tertinggi terjadi pada ruas jalinan AB (T. Iskandar (kota - Kebun Raja) 
dikarenakan banyak terjadi pergerakan dari jalan T. Iskandar (kota). Menurut Anonim (1997), pada umumnya bundaran dengan pengaturan hak jalan (prioritas dari kiri) digunakan di daerah perkotaan dan pedalaman bagi persimpangan antara jalan dengan arus lalu lintas sedang. Pada arus lalu lintas yang tinggi dan kemacetan pada daerah keluar simpang, bundaran tersebut mudah terhalang, yang mungkin menyebabkan kapasitas terganggu pada semua arah.

Tabel 7 Rekapitulasi Arus di tiap-tiap jalinan

\begin{tabular}{ccc}
\hline No. & Bagian Jalinan & $\begin{array}{c}\text { Arus Bagian Jalinan (Q) } \\
\text { (kend/jam) }\end{array}$ \\
\hline 1 & AB & 3184 \\
\hline 2 & BC & 2552 \\
\hline 3 & CD & 2588 \\
\hline 4 & DE & 2389 \\
\hline 5 & EF & 2372 \\
\hline 6 & FG & 2449 \\
\hline 7 & GA & 2557 \\
\hline
\end{tabular}

\subsubsection{Kapasitas Dinamis}

Kapasitas dinamis didapat dari hasil run dengan menaikkan volume untuk mendapatkan arus maksimum diruas jalinan. Selanjutnya, dilakukan distribusi kumulatif $90 \%$ dari volume. Kapasitas dinamis didapat dari hasil perhitungan nilai kumulatif 90 persentil dari distribusi kendaraan atau volume yang didapat dari hasil run.

\subsubsection{Kapasitas Dinamis Maksimum}

Menurut Geistefeldt (2008) konsep dinamis mendukung sebuah metode baru untuk menentukan kapasitas sebagai fungsi yang menggambarkan probabilitas dari kemacetan lalu lintas tergantung pada arus dan kapasitas yang dirancang dapat ditentukan dengan persentil spesifik dari fungsi persebaran.Kapasitas dinamis didasarkan pada distribusi arus lalu lintas yang diobservasi langsung. Untuk menentukan ambang batas yang mendefinisikan sebagai nilai interval 90\%, 95\% dan 99\% dari data yang tersedia. Selanjutnya, distribusi kumulatif dari volume akan dievaluasi pada persentil 85, 90 dan 95 (Chang dan Kim., 2000).Kapasitas dinamis maksimum didapat dari hasil perhitungan nilai kumulatif 90 persentil dari distribusi kendaraan atau volume yang didapat dari hasil run dengan menaikkan volume untuk mendapatkan daya tampung maksimum ruas jalinan. Rekapitulasi kapasitas dinamis maksimum diruas jalinan dapat dilihat pada Tabel 8.

Tabel 8 Rekapitulasi kapasitas dinamis maksimum diruas jalinan

\begin{tabular}{ccc}
\hline No. & Bagian Jalinan & $\begin{array}{c}\text { Kapasitas (C) } \\
\text { (kend/jam) }\end{array}$ \\
\hline 1 & AB & 6427 \\
\hline 2 & BC & 5756 \\
\hline 3 & CD & 6378 \\
\hline 4 & DE & 6629 \\
\hline
\end{tabular}

Studi Rekayasa Lalu Lintas Pada Simpang Tujuh Ulee Kareng Dengan Merencanakan Bundaran (Roundabout) - Ruhdi Faisal, Sugiarto Sugiarto, Zulfhazli, Muhammad Irza 


\begin{tabular}{lll}
\hline 5 & EF & 6548 \\
\hline 6 & FG & 6436 \\
\hline 7 & GA & 6451 \\
\hline
\end{tabular}

\subsubsection{Tundaan}

Berdasarkan hasil simulasi dari VISSIM didapat tundaan tertinggi pada jalinan bundaran yaitu di ruas jalinan AB (T. Iskandar (kota) - Kebun Raja).

Tabel 9 Rekapitulasi Tundaan pada jalinan

\begin{tabular}{ccc}
\hline No. & Bagian Jalinan & Tundaan(detik) \\
\hline 1 & AB & 2,30 \\
\hline 2 & BC & 2,10 \\
\hline 3 & CD & 1,95 \\
\hline 4 & DE & 1,80 \\
\hline 5 & EF & 1,80 \\
\hline 6 & FG & 1,90 \\
\hline 7 & GA & 1,98 \\
\hline
\end{tabular}

\subsubsection{Derajat Kejenuhan}

Derajat kejunahan didapat dari hasil perbandingan arus bagian jalinan dengan kapasitas. Rekapitulasi derajat kejenuah (DS) dapat dilihat pada Tabel 10.

Tabel 10 Rekapitulasi Derajat Kejenuhan

\begin{tabular}{ccc}
\hline No. & Bagian Jalinan & DS $(\mathbf{Q} / \mathbf{C})$ \\
\hline 1 & AB & 0,50 \\
\hline 2 & BC & 0,44 \\
\hline 3 & CD & 0,41 \\
\hline 4 & DE & 0,36 \\
\hline 5 & EF & 0,36 \\
\hline 6 & FG & 0,38 \\
\hline 7 & GA & 0,40 \\
\hline
\end{tabular}

\subsubsection{Peluang Antrian}

Peluang antrian didapat dari pembacaan grafik MKJI (1997 : 4-39), dengan derajat kejenuhan (DS) sebagai data input. Rekapitulasi peluang antrian dapat dilihat pada Tabel 11.

Tabel 11 Rekapitulasi Peluang Antrian

\begin{tabular}{ccc}
\hline No. & Bagian Jalinan & $\begin{array}{c}\text { Peluang Antrian } \\
(\mathbf{Q P \%})\end{array}$ \\
\hline 1 & $\mathrm{AB}$ & $6 \%-13,5 \%$ \\
\hline 2 & $\mathrm{BC}$ & $5 \%-10,5 \%$ \\
\hline 3 & $\mathrm{CD}$ & $4,5 \%-9,8 \%$ \\
\hline
\end{tabular}

Studi Rekayasa Lalu Lintas Pada Simpang Tujuh Ulee Kareng Dengan Merencanakan Bundaran (Roundabout) - Ruhdi Faisal, Sugiarto Sugiarto, Zulfhazli, Muhammad Irza 


\begin{tabular}{ccc}
\hline 4 & DE & $4 \%-8 \%$ \\
\hline 5 & EF & $4 \%-8 \%$ \\
\hline 6 & FG & $4,2 \%-8,5 \%$ \\
\hline 7 & GA & $4,4 \%-9 \%$ \\
\hline
\end{tabular}

Setelah dilakukan pengolahan data seperti yang telah diuraikan sebelumnya maka dapat dilakukan pembahasan mengenai aliran lalu lintas pada Simpang Tujuh Ulee Kareng dengan perencanaan bundaran tipe R10-22 yang telah disimulasikan dengan software VISSIM 6.00-22 dengan melakukan penggandaan random seed sebanyak 15 kali dan melakukan simulation run sebanyak 10 kali terhadap parameter volume lalu lintas, kapasitas, arus bagian jalinan dan tundaan untuk mendapatkan hasil Measurement Of Effectiveness (MOEs) yang akurat. Bundaran yang direncanakan memiliki diameter dalam 20 meter dan diameter luar 42 meter dan dibutuhkan pembebasan lahan seluas $\pm 600 \mathrm{~m} 2$ di sekitar Simpang Tujuh Ulee Kareng.

Hasil simulasi yang dilakukan dengan menggunakan software VISSIM 6.00-22 pada Simpang Tujuh Ulee Kareng adalah kapasitas, arus bagian jalinan dan tundaan sebagai hasil dari node yang dipasang pada tiap-tiap bagian jalinan bundaran. Kapasitas terbesar terdapat di ruas DE (Lamreung - Lamgapang) yaitu $6629 \mathrm{kend} / \mathrm{jam}$. Arus bagian jalinan terbesar terdapat di ruas jalinan AB (T. Iskandar (arah kota) - Kebun Raja) yaitu 3184 kend/jam. Tundaan terbesar terdapat di ruas jalinan AB (T. Iskandar (arah kota) - Kebun Raja) yaitu 2,30 detik/kendaraan. Untuk perhitungan Derajat Kejenuhan (DS) didapat dari perbandingan arus bagian jalinan dengan kapasitas. DS terbesar terdapat dilengan $\mathrm{AB}$ (T. Iskandar (arah kota) - Kebun Raja) yaitu 0,50 dan Peluang Antrian terbesar yang didapat dari pembacaan grafik MKJI adalah 6\%-13,5\% di ruas jalinan (T. Iskandar (arah kota)-Kebun Raja).

Adapun perilaku pengemudi yang menggunakan kalibrasi adalah posisi kendaraan pada saat arus bebas (desired position at free flow), pengaturan perilaku pengemudi pada saat menyiap kendaraan di depannya yaitu dengan mengatur jarak minimum terhadap kendaraan yang akan dinyiap, nilai minimum dari jarak pengemudi saat memberhentikan kendaraan terhadap kendaraan lain, pengaturan jarak aman kendaraan saat melaju dengan kecepatan $50 \mathrm{~km} / \mathrm{jam}$, pengaturan jarak rata-rata terhadap kendaraan lain, jarak aman tambahan saat kondisi normal seperti pengemudi melakukan rem secara mendadak, jarak aman tambahan untuk kondisi tidak normal pada saat mengemudi. Dari hasil simulasi yang telah dilakukan dapat dilihat bahwa Bundaran yang direncanakan memiliki diameter dalam 20 meter dan diameter luar 42 meter dan dibutuhkan pembebasan lahan seluas $\pm 600 \mathrm{~m} 2$ di sekitar Simpang Tujuh Ulee Kareng. Tundaan tertinggi dari hasil simulasi yang dilakukan dengan menggunakan software VISSIM 6.0022 pada Simpang Tujuh Ulee Kareng adalah 2,30 detik/kendaraan di ruas jalinan $\mathrm{AB}$ (T. Iskandar kota - Kebun Raja) masuk dalam kategori tingkat pelayanan A (Peraturan Menteri Perhubungan Nomor KM 14 Tahun 2006. 


\section{Kesimpulan dan Saran}

\subsection{Kesimpulan}

Beberapa kesimpulan yang dapat diambil berdasarkan perencanaan bundaran menggunakan simulasi VISSIM 6.00-22 adalah sebagai berikut:

1. Berdasarkan hasil pengamatan di lapangan selama dua hari pengamatan yaitu Senin (6 Maret 2017) dan Kamis (8 Maret 2017), masing-masing pada waktu pagi pukul 07.00 - 09.00 WIB dan sore pukul 16.30 - 18.30 WIB. Volume tertinggi pada hari Senin (6 Maret 2017) dengan total $4042 \mathrm{kend} / \mathrm{jam}$ yang melintas pada pagi hari pukul 07.00-09.00 WIB dan $4619 \mathrm{kend} / \mathrm{jam}$ pada sore hari pukul 16.30-18.30 WIB.

2. Bundaran yang direncanakan memiliki diameter dalam 20 meter dan diameter luar 42 meter dan dibutuhkan pembebasan lahan seluas $\pm 600 \mathrm{~m}^{2}$ di sekitar Simpang Tujuh Ulee Kareng.

3. Tundaan tertinggi dari hasil simulasi yang dilakukan dengan menggunakan software VISSIM 6.00-22 pada Simpang Tujuh Ulee Kareng adalah 2,30 detik/kendaraan di ruas jalinan AB (T. Iskandar kota - Kebun Raja) masuk dalam kategori tingkat pelayanan A (Peraturan Menteri Perhubungan Nomor KM 14 Tahun 2006 Halaman 21).

4. Adapun dampak dari hasil perubahan eksisting dari pembangunan bundaran adalah berdampak pada kerugian materiil bagi pedagang yang berjualan di sekitar persimpangan tersebut.

\subsection{Saran}

Berdasarkan hasil dan pembahasan serta kesimpulan dapat diberikan bebrapa saran sebagai bentuk rekomendasi sebagai berikut:

1. Untuk peneliti selanjutnya, perencanaan bundaran agar memprediksi arus lalu lintas 5 tahun ke depan.

2. Dari hasil penelitian ini, diharapkan dapat menjadi masukan bagi dinas terkait dalam perencanaan Simpang Tujuh Ulee Kareng dengan bundaran

\section{Daftar Kepustakaan}

Ahmed, 2005, Calibration of Vissim to The Traffic Condition of Khobar and Damman, Saudi Arabia, King Fadh University of Potreleum and Mineral, Saudi Arabia.

Anonim, 1997,ManualKapasitas JalanIndonesia(MKJI). Direktorat Jenderal Bina Marga, Departemen Pekerjaan Umum, Jakarta.

Arasan, V. T., Arkatkar, S. S., 2010. Micro-simulation study of effect of volume and road width on pcu of vehicles under heterogeneous traffic. Journal of Transportation Engineering, 136(12), 1110-1119.

Collins, P., 2009. Paramics MicrosimulationModelling-RTAManual. New South Wales Government. USA.

Geistefeldt, J, 2008, Empirical relationship between stochastic capacities and capacities obtained from the speed-flow diagram. Symposium on the fundamental diagram: 75 years, Monograph 01109339. Woods Hole, Massachusetts, July 8-10, 2008. 
Chang M, Kim, Y., 2000, Development of capacity estimation method from statistical distribution of Observed Traffic Flow, Proceedings: Fourth International Symposium on Highway Capacity, pp 299-309.

Peraturan Menteri Perhubungan Nomor: KM 14 Tahun 2006. Manajemen dan Rekayasa Lalu Lintas di Jalan. Jakarta: Departemen Perhubungan Direktorat Jenderal Perhubungam Darat.

Praveen, P. S., Arasan, V. T., 2013. Influence of traffc mix on pcu value of vehicles under heterogeneous traffc conditions. International Journal for Traffic and Transport Engineering, 3(3), pp. 302-330.

Sonu, M., Dhamaniya, Ashish., Shriniwas., Joshi, Gaurang. 2016. Time occupancy as measure of pcu at four legged roundabouts. Transportation Letters: the International Journal of Transportation Research. Online First.

Sugiarto, Limanond, T. and Nakatsuji, T., 2012. Dropped in capacity and traffic speed of urban Arterial: a case study at u-turn section in Aceh Province, Indonesia. Aceh International Journal of Science and Technology, (3), pp. 86-92.

Sugiarto, S., Limanond, T., 2013. Impact of on-street parking on urban arterial performance: A quantitative study on travel speed and capacity deterioration. Aceh International Journal of Science and Technology, 2(1), pp. 63-69.

Sugiarto, S., Apriandy, F., Faisal, R., Saleh, S.M., 2018. Measuring Passenger Car Unit at Four-Legged Roundabout using Time Occupancy Data Collected from Drone. Aceh International Journal of Science and Technology, 7(2), pp. 77-84.

Troutbeck R., Brilon W., 2001. Unsignalised Intersection Theory Chapter 8, Traffc Flow Theory, A State-of-the-Art Report, Organized by the Committee on Traffc Flow Theory and Characteristics.

VISSIM User Manual-version 8.0. PTV Planing Transport Verkehr AG, Karlsruhe, Germany, 2015. 